\title{
Analysis of color differences between identical tooth shades obtained by a spectrophotometer.
}

\author{
Miguel Rioseco ${ }^{1 *}$, Sonia Wagner ${ }^{1}$ \\ 1. Assistant Professor, School of Dentistry, Faculty \\ of Medicine, Pontificia Universidad Católica de \\ Chile, Santiago, Chile. \\ * Corresponding author: Miguel Rioseco-Ventura \\ | Address: Av. Vicuña Mackenna 4860, Macul, \\ Santiago, Chile | Phone: +569 93198469 | E-mail: \\ mriosecov@uc.cl \\ Work received on 05/10/2020 \\ Revised work 19/12/2020 \\ Approved for publication on 21/01/2021

\begin{abstract}
Introduction. One of the most frequently used color analysis system is the Vita 3D Master toothguide. No study has evaluated if there are color differences between the same Vita 3D Master shades obtained from natural teeth, which could determine changes in the color selection. Objective. To determine $\triangle \mathrm{Eab}$ in natural teeth within the corresponding shade given by a spectrophotometer and compare our results with the AT and PT thresholds reported in the literature. Materials and Methods. We obtained 3818 tooth shade data $\mathrm{L}^{*} \mathrm{a}$ b $\mathrm{b}$ from 200 patients in an ambulatory setting. All color differences $(\triangle \mathrm{Eab})$ between the same Vita $3 \mathrm{D}$ Master shades were registered. Mean, range and standard deviation values were determined. Results. We found a wide dispersion of the $\triangle \mathrm{Eab}$ values within each Vita 3D Master shade. When comparing our results with the PT and AT values available in the literature we found a wide dispersion of the $\Delta$ Eab values, discordant in up to $53 \%$ of the cases. Conclusions. We suggest a revision of the available thresholds. Further research is warranted in this field to improve our understanding of color selection and matching. Clinical significance: The available thresholds for assessing color differences in dentistry probably need to be reviewed.

KEY WORDS

"Color in Dentistry"; "Tooth color"; Color tooth differences; $\Delta$ Eab values.

Int. J. Inter. Dent Vol. 14(3); 233-236, 2021.
\end{abstract}

\section{INTRODUCTION}

Color is one of the most important esthetic parameters in dentistry, and visual judgment is the most frequently used method of evaluating color in dentistry. Different color difference formulas exist, which are designed to provide a quantitative representation of the perceived color difference between two objects within dental research. The most extensively used color difference formula within dental research is derived from the CIE-L*a*b* system $^{(1)}$ which approximates uniformed distances between color coordinates while entirely covering the visual color space:

$$
\left.\Delta \mathrm{E}^{\star}=\sqrt{\left((\Delta L *)^{2}+(\Delta a *)^{2}\right.}+(\Delta b *)^{2}\right) \text { or } \Delta \mathrm{E}^{*}=\left[\left(\Delta \mathrm{L}^{*}\right)^{2}+\left(\Delta \mathrm{a}^{\star}\right)^{2}+\left(\Delta \mathrm{b}^{\star}\right)^{2}\right]^{1 / 2}
$$

$\Delta \mathrm{L}^{*}, \Delta \mathrm{a}^{*}$, and $\Delta \mathrm{b}^{*}$ are the differences in lightness-darkness, green-red coordinate and blue-yellow coordinate, respectively. $\Delta \mathrm{E}^{*}$ is the color difference between two objects, where the higher the value the bigger the difference in color and hence the difference is more perceptible to the human eye. $\Delta \mathrm{E}^{*}$ represents magnitude of the differences in color, but it does not indicate the direction of the color differences. There are two major thresholds for assessing color differences: perceptibility threshold (PT) and acceptability threshold $(\mathrm{AT})^{(2,3)}$. A $50: 50 \%$ PT refers to a situation in which $50 \%$ of observers notice a difference in color between two objects while the other $50 \%$ observers notice no difference. A nearly perfect color match in dentistry is a color difference at or below the 50:50 perceptibility threshold(2).

Analogously, a $50: 50 \%$ AT refers to a situation in which $50 \%$ of the observers consider that the color difference in a patient's mouth requires color correction or fabrication of a new restoration while the other $50 \%$ consider that this difference is acceptable ${ }^{(4)}$. An acceptable color match in dentistry is a color difference at or below the 50:50 acceptability threshold ${ }^{(2)}$.

There have been a number of studies on color perceptibility and acceptability in dentistry evaluating visual thresholds of natural teeth, gingiva and skin, and corresponding restorative materials ${ }^{(5-14)}$. Most of the studies use PT and AT values obtained from in vitro studies that are mainly from the late $80 \mathrm{~s}$.

Khashayar $\mathrm{G}$ et al ${ }^{(13)}$ made a review of in vivo studies who determined perceptibility and acceptability thresholds. All the $\Delta E$ threshold values were obtained by spectrophotometers. Of the 48 studies reviewed, there appeared to be a trend in their source references: $44 \%$ referred to the same study for the $\mathrm{PT}^{(11,15,16)}\left(\Delta \mathrm{E}{ }^{*}=1\right)$ and $35 \%$ referred to the same article for the $\mathrm{AT}(5)\left(\Delta \mathrm{E}{ }^{*}=3.7\right)$. Paravina et $\mathrm{l}^{(17)}$ made the most comprehensive study to date with monochromatic ceramic specimens in simulated setting. The 50:50\% PTs and 50:50\% ATs were significantly different. The CIELAB
$50: 50 \%$ PT in dentistry was found to be $\Delta \mathrm{Eab}=1.2$, whereas the $50: 50 \%$ AT was found to be $\Delta E a b=2.7$. None of the previous studies have evaluated if there are color differences between the same Vita 3D Master shades using the $\triangle$ Eab formula.

Due to the above, the aim of this study was to determine the $\Delta \mathrm{E}$ between the same 3D Master shades obtained from natural teeth by Vita Easyshade $^{\circledR}$ spectrophotometer, (VITA Zahnfabrik, Bad Säckingen, Germany), and compare them with the AT and PT thresholds determined by Paravina $^{(17)}$ and Khaskayar et $\mathrm{al}^{(13)}$.

\section{MATERIALS AND METHODS}

The study used information of dental color of maxillary and mandibullary incisives, canines and premolars obtained from a data base of 200 patients seen in a private clinic. We obtained approval by the Ethics Committee of the Faculty of Medicine of our university ID 200129005 and every patient gave their written consent for their information to be used in this study.

To be included in the study, subjects had to be adult participants, 18-35 years of age, have teeth free of caries and restorations and reasonable alignment within the arch to facilitate shade measurement. . Subjects were excluded if they had tooth discoloration as a result of congenital disease or side effects of medications or if they had been under tooth bleaching within the past 6 months ${ }^{(18,19)}$. The day before the measurements, the facial surface of each tooth was cleaned using polishing brushes and paste. Afterwards, every participant had to thoroughly rinse with water.

Color recordings were performed by one experienced clinician using a Vita Easyshade ${ }^{\circledR}$ spectrophotometer (VITA Zahnfabrik, Bad Säckingen, Germany) according to the manufacturer's instructions. Before each measurement was performed, an infection control shield was placed on the probe tip.

The following measurements were recorded and tabulated:

1. Teeth shade results according to Vita 3D-Master ${ }^{\circledR}$ (VITA Zahnfabrik, Bad Säckingen, Germany) shade guides, obtained by Vita Easyshade.

2. $L^{*}, a^{*}, b^{*}$ values for all teeth obtained by Vita Easyshade.

3. Color differences $\left(\Delta E^{*}\right)$ between the same Vita 3D Master shades were calculated using the following formula: $\Delta \mathrm{E}^{*}=\left[\left(\Delta \mathrm{L}^{*}\right)^{2}+\left(\Delta \mathrm{a}^{*}\right)^{2}+(\Delta\right.$ $\left.\left.b^{*}\right) 2\right]^{1 / 2}$

4. Mean values and standard deviation for color difference $\left(\Delta \mathrm{E}^{*}\right)$ were calculated

5. $\Delta \mathrm{E}^{\star}$ obtained for each color was compared to the PT and AT of the study of Khaskayar et al ${ }^{(13)}$ and Paravina et al ${ }^{(17)}$. 
From the 200 patients we got 3818 tooth shade data $L^{*} a^{*} b^{*}$. All the teeth shades and $L^{*} a^{*} b^{*}$ values were tabulated in excel according to the Vita 3D Master ${ }^{\circledR}$ shade guide nomenclature.

Data was tabulated in number of teeth with a determined tooth shade, $\Delta \mathrm{E}$ minimum and maximum, $\Delta \mathrm{E}$ mean value for each shade and standard deviation, number of teeth within the $\Delta \mathrm{E}$ ranges of the PT and the AT according to Paravina et $\mathrm{al}^{(17)}$ and according to Khaskayar et al ${ }^{(13)}$. See tables and graphics.

Table 1: Results of Vita 3D Master Shade SD (standard deviation). Column 1: $\Delta \mathrm{E}$ lower than PT determined by Paravina et al(17); Column $2: \Delta \mathrm{E}$ in between PT and AT determined by Paravina et al ${ }^{(17)}$; Column 3: $\Delta \mathrm{E}$ higher than AT determined by Paravina et al(17); Column 4: $\Delta \mathrm{E}$ lower than AT determined by Khaskayar et al ${ }^{(13)}$; Column $5: \Delta \mathrm{E}$ ranges in between PT and AT determined by Khaskayar et al(13); Column 6: $\Delta \mathrm{E}$ values higher than AT determined Khaskayar et $\mathbf{a l}^{(13)}$.

\begin{tabular}{|c|c|c|c|c|c|c|c|c|c|c|c|c|c|c|c|c|}
\hline \multirow[b]{2}{*}{$\begin{array}{c}\mathrm{L} \\
\text { shade }\end{array}$} & \multirow[b]{2}{*}{$\begin{array}{l}\text { No of } \\
\text { Loon } \\
\text { shade }\end{array}$} & \multirow[b]{2}{*}{$\begin{array}{l}\text { relatuons } \\
N \circ \triangle E\end{array}$} & \multirow[b]{2}{*}{ 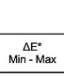 } & \multirow[b]{2}{*}{$\frac{\Delta E^{*}}{\operatorname{Mean}(+-S D)}$} & \multicolumn{2}{|l|}{1} & \multicolumn{2}{|c|}{2} & \multicolumn{2}{|c|}{3} & \multicolumn{2}{|c|}{4} & \multicolumn{2}{|c|}{5} & \multicolumn{2}{|l|}{6} \\
\hline & & & & & $\begin{array}{l}\frac{\Delta E^{*}}{\alpha 1,2} \\
\end{array}$ & $\%$ & 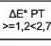 & $\%$ & $\begin{array}{c}\Delta E^{*} \\
A T \\
\rangle=2,7 \\
\end{array}$ & $\%$ & $\begin{array}{l}\Delta E^{\circ} \\
<1\end{array}$ & $\%$ & 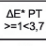 & $\%$ & 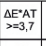 & $\%$ \\
\hline $2 \mathrm{L1}, 5$ & 3 & 3 & $2,1-3,7$ & .13(+-0.89) & 0 & 0.00 & 1 & 33,33 & 2 & 66.67 & 0 & 0.00 & 2 & 66.67 & 1 & 33.33 \\
\hline 1.512 & & & & & & & & & & & & & & & & \\
\hline $2 \ldots 2$ & 121 & 7.260 & $-10,43$ & $2,27(+-1,29)$ & 1.370 & 18,87 & 3.811 & 52,49 & \begin{tabular}{|l|}
2.089 \\
\end{tabular} & 28,77 & 909 & 1252 & 5521 & 76,05 & 830 & 11,43 \\
\hline $22,2,5$ & 74 & 2.701 & $0-13,37$ & $2,911(+-1,95)$ & 370 & 13,70 & 1.172 & 43,39 & \begin{tabular}{|l|}
1.159 \\
\end{tabular} & 42,91 & 240 & 8,89 & 1787 & 66,16 & 674 & 24,95 \\
\hline $2.5 L 1,5$ & 234 & 27.261 & $0-13,02$ & $2,67(t-1.72)$ & 3.966 & 14,55 & 12.874 & 47,22 & \begin{tabular}{|l|}
10.421 \\
\end{tabular} & 38,23 & 2608 & 9,57 & 19308 & 70.83 & \begin{tabular}{|l|}
5.345 \\
\end{tabular} & 19,61 \\
\hline 2.542 & 380 & 72.009 & $0-11,21$ & $2,94(t-1,48)$ & 7.194 & 9,99 & 28.159 & 39,10 & \begin{tabular}{|l|}
36.656 \\
\end{tabular} & 50,90 & 4667 & 6,48 & 47143 & $\begin{array}{ll}65.47 \\
\end{array}$ & \begin{tabular}{|l|}
20.199 \\
\end{tabular} & 28,05 \\
\hline $2,552,5$ & 127 & 8.001 & $0-12,54$ & $2,52(t-1,57)$ & 1.148 & 14,35 & 3.997 & 49,96 & \begin{tabular}{|l|}
2.856 \\
\end{tabular} & 35,70 & 759 & 9,49 & 6161 & 77,00 & \begin{tabular}{|l|l|}
1.081 \\
\end{tabular} & 13,51 \\
\hline $3 L 1,5$ & 147 & 10.731 & $0.13,61$ & $2.25(t-1,49)$ & 1.894 & 17,65 & 6.001 & 55,92 & \begin{tabular}{|l|}
2.836 \\
\end{tabular} & 26,43 & 1241 & 1156 & 8595 & 80,10 & \begin{tabular}{|l|}
895 \\
\end{tabular} & 8.34 \\
\hline 362 & 146 & 10.585 & $0-10.42$ & $2.45(t-1.30)$ & 1.548 & 14.62 & 5.176 & 48.90 & \begin{tabular}{|l|} 
\\
\end{tabular} & 36,48 & 991 & 9.36 & 8130 & 76.81 & \begin{tabular}{|l|l|} 
\\
\end{tabular} & 13.83 \\
\hline $3 L 2,5$ & 91 & 4.095 & $0-9,23$ & $2,48(t+1,23)$ & 585 & 14,29 & 1.933 & 47,20 & 1.577 & 38,51 & 400 & 9,77 & 3061 & 74,75 & \begin{tabular}{|l|}
634 \\
\end{tabular} & 15,48 \\
\hline $3,5\llcorner 1,5$ & 101 & 5.050 & $0-12,58$ & $3,09(t-1,62)$ & 440 & 8,71 & 1.879 & 37.21 & \begin{tabular}{|l|}
2.731 \\
\end{tabular} & 54,08 & 279 & 5,52 & 3215 & 63,66 & 1.556 & 30.81 \\
\hline $3,5 L 2$ & 195 & 18.915 & $0-11,79$ & $3,23(t+1,67)$ & 1.721 & 9.10 & 6.338 & 33.51 & 10.256 & 57,39 & ${ }_{1133}$ & \begin{tabular}{|l|l|}
5,99 \\
\end{tabular} & 11101 & 58,69 & 6.681 & 35,32 \\
\hline $3,552,5$ & & 860 & & $2,31(t-1,19)$ & 156 & 18,14 & 403 & 46,86 & 301 & 35,00 & 102 & \begin{tabular}{|l|l|}
1186 \\
\end{tabular} & 647 & 75,23 & 111 & 12,91 \\
\hline $4 L 1,5$ & 34 & 561 & $0-9,9$ & $2.60(t-1.81)$ & 84 & 14.97 & 278 & 49.55 & 199 & 35,47 & 52 & \begin{tabular}{|l|} 
\\
\end{tabular} & 438 & 78.07 & 490 & 87.34 \\
\hline 426 & 16 & & & & & 5.00 & 55 & 45,83 & 59 & 49,17 & & 3,33 & 89 & & 27 & 22,50 \\
\hline 442,5 & 4 & & & $3,15(t-1.23)$ & & & 2 & 33,33 & 4 & 66,67 & 0 & 0,00 & 3 & & 3 & 50,00 \\
\hline & 1.715 & 168.158 & $0-13,37$ & & \begin{tabular}{|l|l|}
20.482 \\
\end{tabular} & 12,18 & 72.079 & \begin{tabular}{|l|l|}
42,86 \\
\end{tabular} & \begin{tabular}{|l|l|}
75.607 \\
\end{tabular} & 44,96 & 13385 & 7,96 & 115201 & 68,51 & \begin{tabular}{|l|l|}
39.991 \\
\end{tabular} & 23,78 \\
\hline
\end{tabular}

Table 2: Results of Vita 3D Master Shade M SD (standard deviation). Column 1: $\Delta \mathrm{E}$ lower than PT determined by Paravina et al ${ }^{(17)}$; Column $2: \Delta \mathrm{E}$ ranges in between $\mathrm{PT}$ and $\mathrm{AT}$ determined by Paravina et $\mathrm{al}^{(17)}$; Column 3: $\Delta \mathrm{E}$ higher than AT determined by Paravina et al ${ }^{(17)}$; Column 4: $\Delta \mathrm{E}$ lower than AT determined by Khaskayar et al(13); Column 5: $\Delta \mathrm{E}$ ranges in between PT and AT determined by Khaskayar et al(13); Column 6: $\Delta \mathrm{E}$ values higher than AT determined Khaskayar et al ${ }^{(13)}$

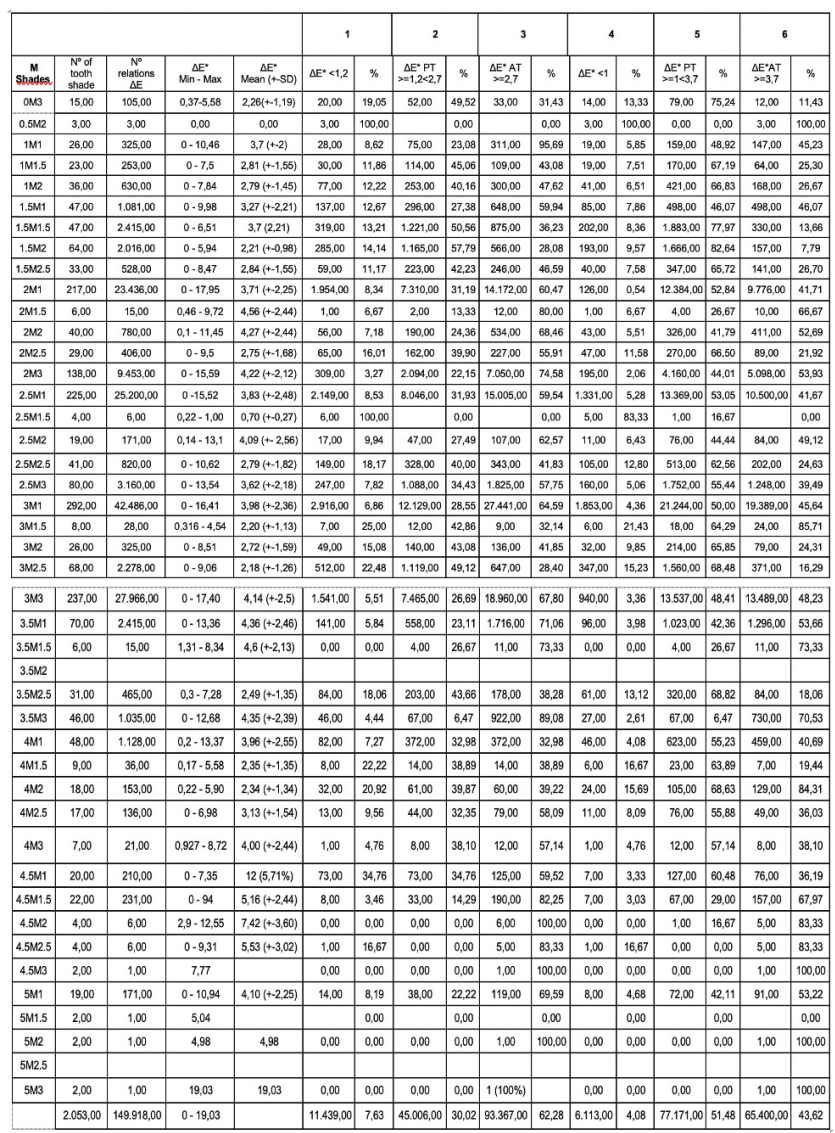

Table 3: Results of Vita 3D Master Shade R SD (standard deviation). Column 1: $\Delta \mathrm{E}$ lower than PT determined by Paravina et $\mathrm{al}^{(17) ;}$ Column $2: \Delta \mathrm{E}$ ranges in between PT and AT determined by Paravina et al ${ }^{(17)}$; Column 3: $\Delta \mathrm{E}$ higher than AT determined by Paravina et al (17); Column 4: $\Delta \mathrm{E}$ lower than AT determined by Khaskayar et al(13); Column 5: $\Delta \mathrm{E}$ ranges in between PT and AT determined by Khaskayar et al ${ }^{(13)}$; Column 6: $\Delta \mathrm{E}$ values higher than AT determined Khaskayar et al ${ }^{(13)}$
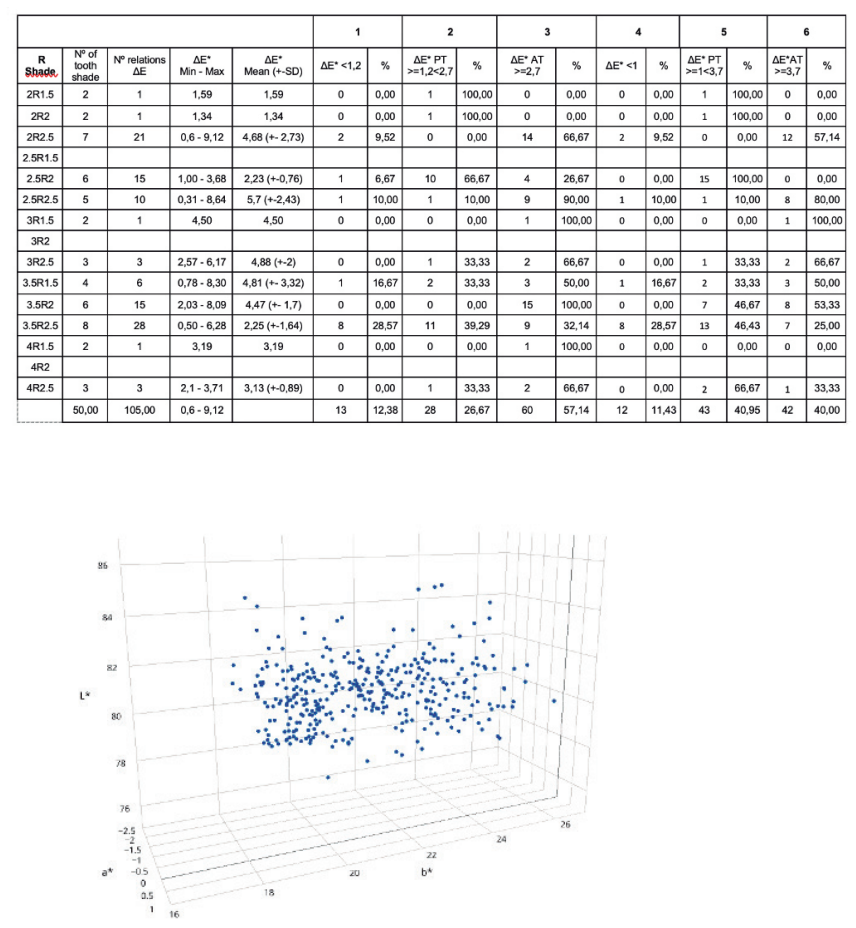

Graph 1: Values of $L^{*} a^{*} b^{*}$ given by Vita Easyshade ${ }^{\circledR}\left(V_{I T A}\right.$ Zahnfabrik, Bad Säckingen, Germany) for 2.5L2 color $(n=380)$

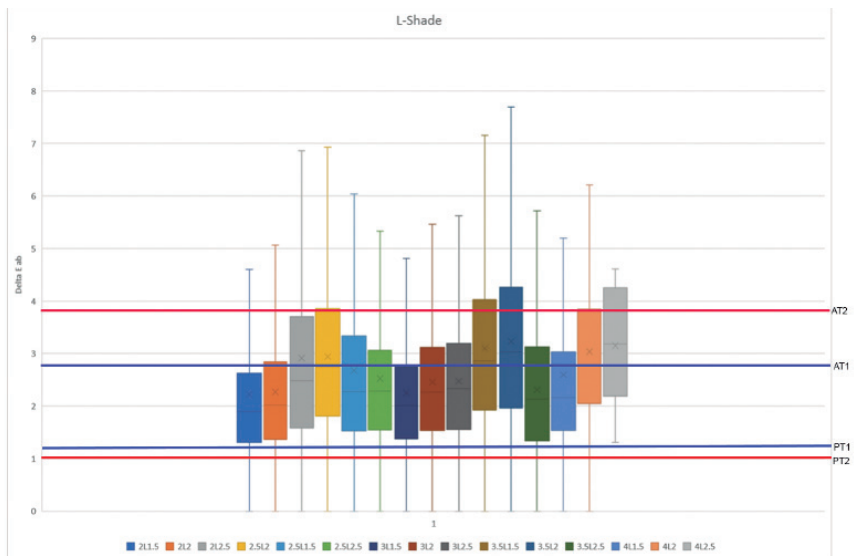

Graph 2: $\Delta \mathrm{E}$ minimum and maximum, $\Delta \mathrm{E}$ mean value, $\Delta \mathrm{E}$ ranges of the PT and the AT for Vita 3D Master Shade L; AT1: AT corresponding to Paravina et al ${ }^{(17)}$, AT2: AT corresponding to Khaskayar et al ${ }^{(13)}$, PT1: PT corresponding to Paravina et al ${ }^{(17)}$, PT2: PT corresponding to Khaskayar et $\mathrm{al}^{(13)}$ 


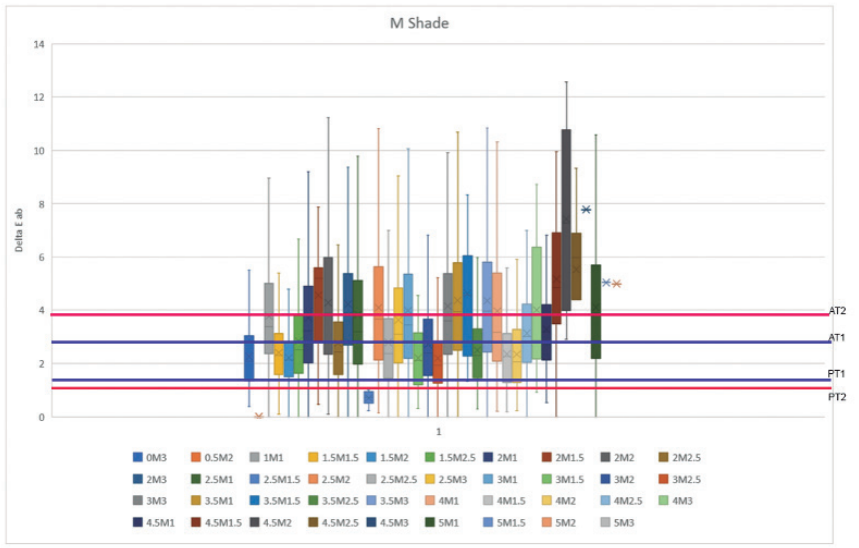

Graph 3: $\Delta \mathrm{E}$ minimum and maximum, $\Delta \mathrm{E}$ mean value, $\Delta \mathrm{E}$ ranges of the PT and the AT for Vita 3D Master Shade M; AT1: AT corresponding to Paravina et al ${ }^{(17)}$, AT2: AT corresponding to Khaskayar et al ${ }^{(13)}$, PT1: PT corresponding to Paravina et $\mathrm{al}^{(17)}$, PT2: PT corresponding to Khaskayar et $\mathrm{al}^{(13)}$

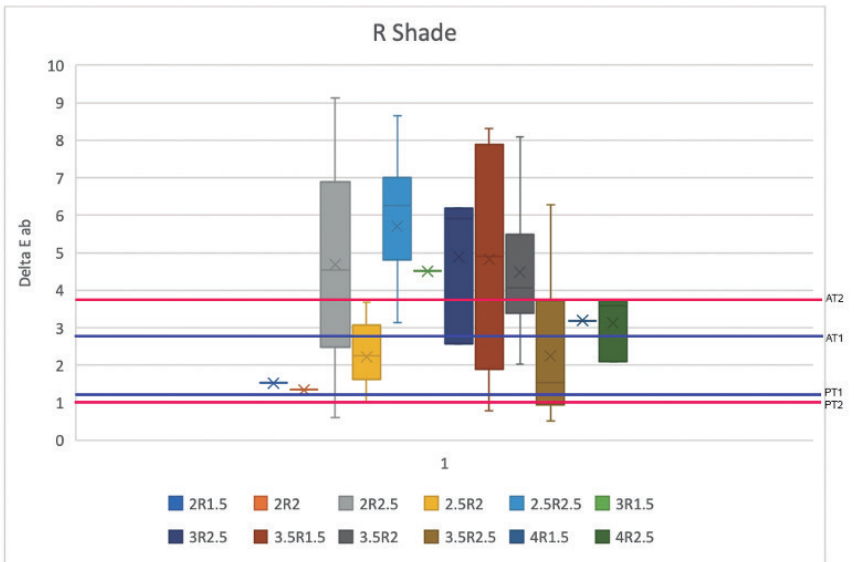

Graph 4: $\Delta \mathrm{E}$ minimum and maximum, $\Delta \mathrm{E}$ mean value, $\Delta \mathrm{E}$ ranges of the PT and the AT for Vita 3D Master Shade R; AT1: AT corresponding to Paravina et al ${ }^{(17)}$, AT2: AT corresponding to Khaskayar et al ${ }^{(13)}$, PT1: PT corresponding to Paravina et $\mathrm{al}^{(17)}$, PT2: PT corresponding to Khaskayar et al ${ }^{(13)}$

\section{RESULTS}

The most frequent colors of the 3818 tooth shades were: $2.5 \mathrm{~L} 2$ (9.95\%); 3M1 (7.64\%); 3M3 (6.2\%); 2.5L1.5 (6.12\%); $2.5 \mathrm{M} 1$ (5.8\%). 1.715 samples (44.9\%) were L tooth shades, $2053(53.7 \%)$ were M tooth shades and only $50(1.3 \%)$ were R tooth shades. $41 \%$ of the tooth color shades of this study had match with the 26 colors of the 3D Master Toothguide and Linearguide, while $60.84 \%$ presented intermediate shades that were not physically represented in the toothguides.

The $L^{*} a^{*} b^{*}$ values obtained for the same color were different and disperse. One example of that can be seen in Graph 1, which shows the different values of $L^{*} a^{*} b^{*}$ given by Vita Easyshade ${ }^{\circledR}$ spectrophotometer (VITA Zahnfabrik, Bad Säckingen, Germany) for $2.5 \mathrm{~L} 2$ color.

The results of the Vita 3D Master Shade L, M and $R$ are presented in Tables 1,2 and 3. Graphs 2,3 and 4 represent the values presented in the corresponding tables.

The range of $\Delta \mathrm{E}$ of the total of teeth shades was between 0 and 19.3. $10 \%$ of the total $\Delta \mathrm{E}$ are lower than the $\Delta \mathrm{E} P T$ described by Paravina et al(17); $36.8 \%$ of the total $\Delta \mathrm{E}$ are in between the range of $>=1.2$ and $<2.7$ but $53.2 \%$ of our values are higher than the maximum $\Delta \mathrm{E}$ AT of 2.7 reported by the same authors. Comparing our results against Khaskayar et al ${ }^{(13)}$, $6.13 \%$ of our $\Delta \mathrm{E}$ are lower than their $\Delta \mathrm{E} \mathrm{PT} ; 60.4 \%$ are in the range of $>=1$ and $<3.7$ and $33.13 \%$ of our values are higher than the maximum $\Delta E$ AT of 3.7 obtained by them ${ }^{(13)}$.

When we study each shade independently, we observe that in the $\mathrm{R}$ shades, $12.38 \%$ of our $\Delta \mathrm{E}$ values are lower than $\Delta \mathrm{E}$ PT described by Paravina et al ${ }^{(17)} ; 26.67 \%$ are $>=1.2$ and $<2.7$ and $57.14 \%$ of our values are equal or higher than the maximum reported $\Delta \mathrm{E}$ AT of 2.7. On the other hand, $11.43 \%$ of our $\Delta \mathrm{E}$ values are lower than $\Delta \mathrm{E}$ PT described by Khas- kayar et $\mathrm{al}^{(13)} ; 40.95 \%$ are $>=1$ and $<3,7$ but $40 \%$ of our values are equal or higher than the $\Delta \mathrm{E}$ AT of 3.7 obtained by them 27 .

In the $\mathrm{L}$ shades, $12.18 \%$ of our $\Delta \mathrm{E}$ values are lower than $\Delta \mathrm{E} P T$ described by Paravina et al ${ }^{(17)} ; 42,86 \%$ are $>=1,2$ and $<2,7$ and $44,96 \%$ of our values are equal or higher than the $\triangle \mathrm{E} A \mathrm{AT}$ of 2.7 obtained by the same authors.

On the other hand, $7.96 \%$ of our values are lower than the $\triangle \mathrm{E} P \mathrm{PT}$ described by Khaskayar et al(13); $51 \%$ are $>=1$ and $<3.7$ and $23.78 \%$ of our values are equal or higher than the $\Delta \mathrm{E}$ AT of 3.7 obtained by them.

In the $\mathrm{M}$ shades, $7.63 \%$ of the obtained values are lower than $\triangle \mathrm{E} P T$ described by Paravina et al ${ }^{(17)} ; 30.02 \%$ of the obtained values are $>=1,2$ and $<2,7$ but $62.28 \%$ of our values are equal or higher than the maximum reported $\triangle \mathrm{E}$ AT of 2.7 obtained by the same authors. On the other hand, $4.08 \%$ of our values are lower than $\Delta \mathrm{E}$ PT described by Khaskayar ${ }^{(13)}$; $51.48 \%$ are $>=1$ and $<3.7$ and $43.62 \%$ of our values are equal or higher than the $\triangle \mathrm{E}$ AT of 3.7 obtained by them.

\section{DISCUSSION}

Visual thresholds are a beneficial quality-control tool for several industries and applications. Color matches at or below 50:50\% PT would be ideal, but achieving a non-perceivable match is costly, time-consuming, and frequently not essential. The $50: 50 \%$ AT, on the other hand, is of ultimate importance as a predictor of product acceptability, in our case dental restorations. The "cushion" difference between those two thresholds is called industry acceptance color difference ${ }^{(14)}$. However, there is no consensus on the gold standard for the thresholds of perceptibility and acceptability in dentistry.

These thresholds can serve as a quality control tool to guide the selection of dental materials, evaluate their clinical performance, and interpret visual and instrumental findings in clinical dentistry, dental research, and subsequent standardization. In dentistry, acceptability thresholds for color differences are higher than perceptibility thresholds ${ }^{(5,6)}$ Visual thresholds greatly supplement traditional descriptive and analytical statistics in color research. Perceiving a difference in color and whether this difference is acceptable or not is of paramount importance and has been used in dental research for interpreting bleaching efficacy, comparing visual and instrumental shade matching, dental shade guides, and other areas related to color compatibility, color stability, and color interaction ${ }^{(3,20)}$

Although clinical shade matching is routinely performed by a visual method, color parameters measured by an instrument may provide information that can enhance the accuracy of color matching ${ }^{(21,22)}$. Most shade-matching devices have similar high reliability (over $96 \%$ ), indicating predictable shade values from repeated measurements. But there is a high variability in accuracy among devices. The instrument that has been used for measuring the tooth color is the spectrophotometer. It can be considered the gold standard of color measuring devices ${ }^{(23)}$ excluding any discussion on the comparability of data. The Vita Easyshade ${ }^{\circledR}$ (VITA Zahnfabrik, Bad Säckingen, Germany) is an intraoral dental spectrophotometer and shows the best accuracy ${ }^{(24)}$. When used in an appropriate mode, it will provide CIELAB value, chroma, hue and the closest 3D-Master or Classical Vita shade. Each 3D-Master shade has different $L^{*} a^{*} b^{*}$ values.

Ishikwa-Nagai et al(7) established a need for standardization of acceptability and perceptibility thresholds and aimed to set a gold standard for the color difference at which all-ceramic crowns cannot be distinguished from natural teeth. As more and more research is performed on color science in dentistry, there appears to be no consensus on the thresholds of perceptibility and acceptability ${ }^{(13)}$.

To the best of our knowledge, there is no available article which evaluates differences in color for the same vita shades. In our study, we found a wide dispersion of the $\Delta \mathrm{E}$ values which were not in accordance with the PT and AT values obtained by the studies of Paravina et $\mathrm{al}^{(17)}$ and Khaskayar et $\mathrm{al}^{\left({ }^{(13)} .\right.} 53.2 \%$ of the $\Delta \mathrm{E}$ values that we calculated from the data obtained by Vita Easyshade ${ }^{\circledR}$ (VITA Zahnfabrik, Bad Säckingen, Germany) are bigger than the AT threshold determined by Paravina RD ${ }^{(17)}$. If we compare our results with the AT threshold obtained by Khaskayar et $\mathrm{al}^{(13)}, 33.13 \%$ of our $\Delta \mathrm{E}$ values are bigger than their results. Therefore, a high percentage of colors would have been rejected when using the $\Delta \mathrm{E}$ AT obtained by the two aforementioned studies.

The prevalence of intermediate shades is bigger than the colors that are actually present in the 3D Master Toothguide and Linearguide. We found a prevalence of $60.84 \%$ for intermediate shades, similar to Gómez-Polo ${ }^{(25)}$ who pointed out that the intermediate colors not physically present in the toothguides represented $60 \%$ of the sample. The absence of these colors represents a real problem for the clinician and technician because there is no physical representation of them in the toothguide. It would be advisable to develop high quality softwares to create digital toothguides that cover the entire spectrum of shades. 
One of the limitations of the study is that the sample size of the Vita 3D Master shade $R$ is smaller than the $M$ and $L$ shade groups. The ideal situation would be to have similar sample sizes for every shade. Additional limitations include variations in the color measurements due to irregularities present in the tooth surface, and the different age of the patients.

Vita Easyshade ${ }^{\circledR}$ (VITA Zahnfabrik, Bad Säckingen, Germany) works comparing the $L^{*} a^{*} b^{*}$ values of the tooth with the closest 3D-Master or Classical Vita $L^{*} a^{*} b^{*}$ value. This is how it selects the nearest color of the toothguide and the reason why one Vita 3D-Master color could have different and very disperse $L^{*}{ }^{*}{ }^{*}{ }^{*}$ values. Despite the above, the color selected by Vita Easyshade ${ }^{\circledR}$ (VITA Zahnfabrik, Bad Säckingen, Germany) gives an optimal aesthetic result ${ }^{7-10,21,22)}$. While color measuring instruments continue to improve, they still do not replace the operator. Instead, color matching instruments provide the dental professional with an objective tool to confirm a "best match" among various shade guides.

To obtain the exact color of a tooth with intermediate values, we recommend using a Bleachedguide sample with the following boards: $1 \mathrm{M} 2$; $1.5 \mathrm{M} 2 ; 2 \mathrm{M} 2 ; 2.5 \mathrm{M} 2 ; 3 \mathrm{M} 2 ; 3.5 \mathrm{M} 2 ; 4 \mathrm{M} 2 ; 4.5 \mathrm{M} 2 ; 5 \mathrm{M} 2$ adding the $0 \mathrm{M} 2$ board. Once you obtain the correct value parameter, you can use the Vita 3D Master guide or Linearguide to choose the hue and chroma parameters.

In summary, the $\Delta \mathrm{E}$ values that we calculated from the data obtained by Vita Easyshade ${ }^{\circledR}$ (VITA Zahnfabrik, Bad Säckingen, Germany) are big- ger than the AT threshold determined by Paravina et al ${ }^{(17)}$ and Khaskayar et $\mathrm{al}^{(13)}$. These data together with the fact that the color selected by Vita Easyshade $^{\circledR}$ (VITA Zahnfabrik, Bad Säckingen, Germany) gives an optimal aesthetic result would indicate that a modification of the acceptability and perceptibility thresholds is needed. Finally, as Rade Paravina said "Color Objective is good only if it matches Subjective", you need to compare the instrumental shade result with the visual shade results to get the real color match. Ultimately, the best color matching tool would be the one whose results correspond to a clinician's normal color vision. Further research is needed in this field to improve our understanding of color selection and matching.

\section{FINANCIAL SUPPORT}

The study did not receive any financial support.

\section{ACKNOWLEDGEMENTS}

We would like to thank Dr. Emilio Wagner, M.D, for his assistance with the revision of the article.

\section{CONFLICTS OF INTEREST STATEMENT}

The authors report no conflicts of interest related to this study.

\section{References}

1. CIE ICol. Colorimetry: official recommendations of the international commission on illumination. Paris: Bureau Central de la CIE; 1971.

2. International Organization for Standardization. Dentistry-guidance on color measurement. ISO/TR 28642 Geneva: International Organization for Standardization; 2016.

3. Pérez MM, Ghinea R, Herrera LJ, et al. Dental ceramics: a CIEDE2000 acceptability thresholds for lightness, chroma and hue differences. J Dent. 2011;39(Suppl 3): e37-44. 4. Paravina RD. Critical appraisal. Color in dentistry: improving the odds of correct shade selection. J Esthet Restor Dent. 2009;21(3):202-8.

5. Johnston WM, Kao EC. Assessment of appearance match by visual observation and clinical colorimetry. J Dent Res. 1989;68(5):819-22.

6. Douglas RD, Brewer JD. Acceptability of shade differences in metal ceramic crowns. J Prosthet Dent. 1998;79(3):254-60.

7. Ishikawa-Nagai S, Yoshida A, Sakai M, et al. Clinical evaluation of perceptibility of color differences between natural teeth and all-ceramic crowns. J Dent. 2009;37(Suppl 1):e57-63.

8. Wee AG, Lindsey DT, Shroyer KM, Johnston WM. Use of a porcelain color discrimination test to evaluate color difference formulas. J Prosthet Dent. 2007;98(2):101-9.

9. Alghazali N, Burnside G, Moallem M, et al. Assessment of perceptibility and acceptability of color difference of denture teeth. J Dent .2012;40 Suppl 1:e10-7. 10. Ragain JC, Johnston WM. Color acceptance of direct dental restorative materials by human observers. Color Res Appl. 2000;25(4):278-85.

11. Ruyter IE, Nilner K, Moller B. Color stability of dental composite resin materials for crown and bridge veneers. Dent Mater. 1987;3(5):246.51.

12. Douglas RD, Steinhauer TJ, Wee AG. Intraoral determination of the tolerance of dentists for perceptibility and acceptability of shade mismatch. J Prosthet Dent 2007;97(4):200-8.

13. Khashayar $G$ el al. Perceptibility and acceptability thresholds for colour differences in dentistry. J Dent. 2014;42(6):637-44.
14. Thoma DS et al. Threshold values for the perception of color changes in human teeth. Int J Periodontics Restorative Dent. 2016;36(6):777-83.

15. Seghi RR, Hewlett ER, Kim J. Visual and instrumental colorimetric assessments of small color differences on translucent dental porcelain. J Dent Res. 1989;68(12):1760-4.

16. Kuehni RG, Marcus RT. An experiment in visual scaling of small colour differences. Colour Research and Application. 1979;4(2):83-91.

17. Paravina RD. Color Difference Thresholds in Dentistry J Esthet Restor Dent 2015;27 Suppl1:S1-9.

18. Fondriest J. Shade matching in restorative dentistry: the science and strategies. Int J Periodontics Restorative Dent. 2003;23(5):467-79.

19. Russell MD, Gulfraz M, Moss BW. In vivo measurement of color changes in natural teeth. J Oral Rehabil. 2000;27(9):786-92.

20. Moon A, Powers JM, Kiat-Amnuay S. Color stability of denture teeth and acrylic base resin subjected daily to various consumer cleansers. J Esthet Restor Dent. 2014;26(4):247-55.

21. Paul SJ, Peter A, Rodoni L, Pietrobon N. Conventional visual vs spectrophotometric shade taking for porcelain-fused-to-metal crowns: a clinical comparison. Int J Periodontics Restorative Dent. 2004;24(3):222-31.

22. Liberato WF et al. A comparison between visual, intraoral scanner, and spectrophotometer shadematching: A clinical study. J Prosthet Dent. 2019;121(2):271-5.

23. Dozic A, Kleverlaan CJ, El-Zohairy A, Feilzer AJ, Khashayar G. Performance of five commercially available tooth color-measuring devices. J. Prosthodont 2007;16(2):93-100.

24. Kim- Pusateri S. Reliability and accuracy of four dental shade-matching devices. J Prosthet Dent. 2009;101(3):193-9.

25. Gomez-Polo C et al: Study of the most frequent natural tooth colors in the Spain population using spectrophotometry. J Adv Prosthodont. 2015;7(6):413-22. 